\title{
Undergraduate Students' Attitudes towards Online Language Classes during the COVID- 19 Pandemic: Are Students Thriving or Surviving?
}

\author{
Jokha Al Hosni ${ }^{1} \mathbf{8}(D)$ and Wafa Al Dhahli ${ }^{2} \mathbf{8}$ (D) \\ ${ }^{12}$ Center for Preparatory Studies, Sultan Qaboos University, Muscat, Sultanate of Oman \\ $\triangle$ Corresponding Author: Jokha Al Hosni, E-mail: alhosnij@squ.edu.om
}

\author{
ARTICLE INFORMATION \\ Received: August 11, 2021 \\ Accepted: September 16, 2021 \\ Volume: 3 \\ Issue: 10 \\ DOI: $10.32996 /$ jeltal.2021.3.10.3
}

\section{KEYWORDS}

Attitudes, Covid-19 pandemic, e-learning, ELT, online learning, undergraduates

\section{ABSTRACT}

The global pandemic has tremendously affected all walks of life. Education is no exception, with online learning being the only available mode of learning. This sudden shift to online learning, which was given marginal attention before the pandemic, has entailed many challenges for decision-makers, teachers and students alike. This paper highlights the general attitudes of Omani undergraduate students towards online language courses amid the COVID-19 pandemic. The participants are 155 undergraduate students who took online English requirements in the Centre for Preparatory Studies (CPS) at Sultan Qaboos University (SQU) in Spring 2021. A quantitative approach to data collection has been embraced to collect students' perspectives on different aspects related to their online learning experience. A survey addressing different aspects of online learning related to connectivity, communication, learning experience and learning environment, assessment and learner's online identity was conducted. The findings show that students are thriving and have a general positive attitude towards the online learning experience. However, students reported some factors which made the online instruction stressful such as technical issues, marathon assignments, disconnectedness and online identity. The findings of the study can be good indicators that should be taken into consideration when designing, running and evaluating online language courses for undergraduate students to help them thrive during this mode of learning.

\section{Introduction}

During the COVID-19 pandemic, switching to online learning was the only safe and logical solution to control the spread of the virus as well as keep offering education to students, especially at the tertiary level. It cannot be denied that at the time of crisis, information technology tools have played the role of a panacea for fast relief of the sudden disturbance of the education process (Mahyoob, 2020). Nevertheless, some educators described this transition as being 'forced' (Asmara, 2020) on them to shift to a 'sudden' and 'uncertain' (Hapsari, 2021) virtual learning experience. Statistics around the world showed that many tertiary institutions were not prepared to shift to online learning as a consequence of COVID-19 outbreak; therefore, they had to overcome this emergency situation by relying on low-tech solutions (Díaz \& Lee, 2020; Li \& Lalani, 2020). They relied mainly on video conferencing via Zoom or similar tools of communication to be able to end the semester. These pieces-together measurements to face the disruption of the educational process gave the impression that online learning is chaotic and challenging which is not true when online courses are carefully designed and planned for this purpose.

The term E-learning (Electronic learning) has been interchangeably used with online learning, distance learning, remote learning, mobile learning and virtual learning. In fact, it is believed that there are 23 identified concepts used to refer to the use of computer devices for learning purposes (Berrocoso et al., 2020). E-learning is a set of synchronous and/or asynchronous learning experiences that are delivered via different devices such as laptops and smartphones (Dhawan, 2020). In synchronous learning, live sessions are used to have real time interaction between the teacher and students, whereas, in asynchronous learning, other learning platforms are utilized, namely Moodle, Blackboard and Google Classroom. These virtual spaces host all learning

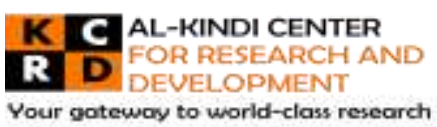

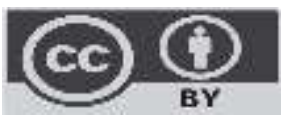

Published by Al-Kindi Center for Research and Development, United Kingdom. Copyright (c) the author(s). This open access article is distributed under a Creative Commons Attribution (CC-BY) 4.0 license 
activities that give both teachers and learners the flexibility of time that synchronous sessions do not usually allow. Since elearning is a key concept in this research study, it is worth mentioning that the terms distance education, online learning and virtual learning will be used in this paper as synonyms for e-learning.

This paper will start with a literature review section that will highlight two main parts: the first part will be about e- learning before the COVID-19 pandemic while the second part will discuss e-learning during the recent pandemic in terms of advantages, challenges and solutions. Students' perceptions will be highlighted when the three aspects are discussed in the literature review section. The second section of the paper will thoroughly discuss the quantitative study: the participants, methodology, results and discussions and the recommendations.

The findings of this study may come with some limitations. The data were based on participants from the CPS population. Students in higher education (HE) institutions in Oman share mostly the same demographic background and digital infrastructure which should make the findings reflective of the general attitude of the undergraduate students towards online learning during COVID-19. However, having a diverse population from different government and private HE institutes would be more enlightening. Besides, due to the timing of the research study, which was at the end of the semester, it was not feasible to get more in-depth insights from the participants through interviews.

\section{Literature Review}

\subsection{E-learning in the pre-COVID-19 Education}

Before the COVID-19 pandemic, there was already an increasing interest in educational technology, with global EdTech investments of around US $\$ 18.66$ billion in 2019. This includes video conferencing and virtual tutoring tools, educational apps and online learning software (Li \& Lalani, 2020). Prior to the outbreak of COVID-19, distance learning witnessed a small but steady growth. For example, $34.7 \%$ of college students in the USA were enrolled in at least one online course in 2018 (The Revolution of Distance Education, 2020, Para 5). However, distance learning was an option rather than a necessity in most educational settings around the world considering all the restrictions of distance learning and the feasibility and reliability of conventional face-to-face learning. Consequently, most educational institutions were unprepared to switch to online learning after the outbreak of the pandemic.

Prior to the pandemic, a large volume of research was devoted to distance learning. Different aspects were investigated in literature to explore students' perceptions towards online language classes, such as connectivity and accessibility, materials and assignments delivery and level of anxiety. However, one major element that influences students' perceptions towards online classes is the level of teacher-student and student-student interaction. A 2015 study done to investigate 249 undergraduate students' perceptions of online classes revealed that the level of interaction between the students and their teacher affected their level of satisfaction (Fedynich at al., 2015). Sun (2014) identified six major challenges in online English as a Foreign Language (EFL) classes. Four of which are on engagement with peers through pair and collaborative work. He stated that the feelings of disconnectedness and isolation in virtual classes could affect students' attitudes toward online learning and, therefore, reduce their enthusiasm and motivation. This is because it is believed that collaborative interaction is the "heart and soul of an online course" (Draves,2002, as cited in Sun, 2014).

In a study done among 47 undergraduate students in online preparatory English classes in Turkey, the results showed that participants had partly positive attitudes toward their online classes. With regard to language skills in online classes, $55.3 \%$ of the participants had difficulties in writing activities. Listening activities came next as their second most difficult language skill to comprehend online. On the other hand, they gave positive feedback regarding their reading, vocabulary and grammar activities (Erarslan \& Topkaya, 2017).

Tuncay \& Uzunboylu (2010) surveyed 120 undergraduate students to explore the level of anxiety and resistance to distance learning across both genders. The findings revealed different types of anxiety. Students listed online- test anxiety and internet anxiety as the top two types they encountered, with higher anxiety levels among girls.

Social identity is another topic that was highlighted in the literature. In her article, Al Hosni (2013) discussed some issues related to English as a Second Language (ESL) learners' social identities in online classes which are anonymity, social presence, forced individualism and muting. Many studies have indicated that anonymity is a factor that helps students feel more comfortable and safer in an online environment (Fong, 2008; Gunn et al., 2003; Lam, 2004; Michinov et al., 2004; Sullivan, 2002). Anonymity is a major advantage for language learners, in particular, because they find practicing the new language less challenging and "because of online anonymity, language learners do not only participate more often online, but they also feel more comfortable contributing and less concerned about making mistakes." (Al Hosni, 2013, p. 30).

Two types of muting were highlighted in the article: self-muting and imposed muting. Self-muting takes place when the learners choose to limit their participation because of the anxiety they experience when they feel that their language proficiency level is 
inadequate. Imposed muting, on the other hand, occurs when a learner's opinions or comments are deliberately ignored by other participants who tend to have a better proficiency level.

\subsection{E-learning at SQU}

At SQU, according to the 2019 annual report, 623 academic staff and more than 15,000 students used Moodle, the open-source learning platform used in the university (SQU Annual Report, 2019, p. 33). Before the pandemic, Moodle was used widely by various courses across SQU to provide extra resources that complement the paper coursebooks as well as conduct online quizzes. In the Centre for Preparatory Studies (CPS), where this research study was conducted, the use of Moodle was essential in most of the courses in both foundation program and credit courses (English courses that are college requirements). Students were asked to enroll in their Moodle course's page from the first week of the semester to have access to many resources. Most of the courses in the center require students to complete weekly quizzes that contribute to their final grade in addition to many other graded and non-graded self-paced tasks. Therefore, it is believed that asynchronous learning via Moodle was not a sudden shift for the CPS students. Synchronous learning, however, is a totally new experience for SQU.

\subsection{E-learning During COVID-19}

This pandemic has undoubtedly affected the ELT curriculum at SQU as well as the teaching methods and instructors' professional development in different ways. To start with, SQU administration decided that all courses would be taught asynchronously during Emergency Remote Teaching (ERT) in Spring 2020. This required making the teaching materials accessible to students online. According to Osman (2020), for the past 18 years, barely $41 \%$ of courses offered by the College of Education had online components. Nevertheless, this percentage went up to $100 \%$ during the ERT period. A lot of technical support and training was offered by the Centre for Educational Technology to SQU staff to help them move from the conventional face-to-face teaching to online instruction. The asynchronous classes offered the students the flexibility to view the online materials at their convenience. The differences between ERT and online teaching in terms of assessment and design have been noted in the literature by some scholars (Al Damen, 2020, Khlaif \& Salha, 2020; Shisley, 2020). ERT is a fast and immediate shift from a faceto-face mode of teaching to a virtual format as a response to an emerging crisis which is completely different from online courses intentionally developed to be taught on virtual platforms. (Hodges. et al, 2020).

At SQU, there was sufficient time during summer 2020 to make the necessary adjustments to the foundation and credit courses to be delivered online for the new academic year 2020/2021. The official platform used at SQU is Moodle which has been utilized to display soft copies of teaching materials as well as online interactive quizzes and assignments. Some classes were offered synchronously while others were offered asynchronously. Google Classroom and Google Meet were two tools used to deliver classes synchronously. The Covid-19 pandemic did affect the ELT curriculum in the CPS by shifting the content from face-to-face to interactive virtual content. This shift to online teaching relied heavily on the integration of technology and came with many challenges. It was observed that the interaction between the teachers and their students as well as the interaction among the students themselves was minimal. This resulted in the difficulty to distinguish high achievers from low achievers, a task that was more feasible during face-to-face interaction. This precluded student from receiving additional assistance from their teachers to accommodate their academic needs. As a result, SQU has decided to implement synchronous teaching in Fall 2020 to ensure better learning outcomes.

The recent literature on teaching online during COVID-19 explored advantages and challenges observed by different educators. Solutions were sometimes proposed to overcome these obstacles to make the virtual learning experience smoother and more efficient for teachers and students. Therefore, this part of the literature review will shed light on these three aspects.

Zhao (2003) pointed out that the success of online learning depends on many variables, and the learner is the main factor. Positive attitudes of students are essential towards the acceptance and adoption of online learning (Ullah et al., 2017). Therefore, students' perceptions are highlighted when the three aforementioned aspects are discussed below.

\subsection{Advantages}

Online learning has many advantages, such as making education accessible globally and saving resources. Flexibility is one major benefit of virtual learning (Barker, 2020). For example, recorded classes can be revisited by students at any time. The need to record sessions challenges teachers to be well-prepared. This pushes them to improve their teaching methods which contributes to their professional development. Interestingly, there is a generally positive attitude among students towards online learning during COVID-19 despite the challenges students encountered during the process. For example, a recent study done among 66 Indonesian college students to explore their perceptions of online English language classes revealed a relatively high level of participation and involvement in online classes (Agung, 2020). Despite the connectivity problems, about $94 \%$ of the students managed to stay involved in their classes. A similar study done among 184 Saudi undergraduate students agrees with the findings of Agung et al. study. Mahyoob (2020) stated that $43 \%$ of the students were satisfied with their online language classes 
and around the same percentage (42.9\%) of them were somehow satisfied. These positive attitudes towards virtual learning can be attributed to the fact that learners and educators nowadays are expected to be less challenged to access virtual learning tools as they have experimented with educational technology tools using their computers or smart devices (Pellegrini, Mirella, Uskov, \& Casalino, 2020, as cited in Mahyoob, 2020). Prensky (2001) described learners 20 years ago as 'native speakers of the technological language.' (p.1). For instance, Mahyoob's study revealed that WhatsApp was an effective alternative tool to submit and receive assignments when the main platform tools (blackboard) were not accessible to students. Similar results were revealed by a study conducted in Indonesia among college students where WhatsApp was the most preferable e-learning platform, followed by Google Classroom. The researchers indicated that students prefer to use WhatsApp because it does not require much data, they have it installed on their mobile devices, and they are already familiar with it (Agung, 2020). These findings go in line with the favorable impact of integrating social media into online teaching observed and stated in the existing literature (Kaid \& Bin-Hady, 2019).

\subsection{Challenges}

Khlaif and Salha (2020) highlighted some crucial aspects to consider during online instruction such as the teaching materials, virtual equity, and digital privacy. They stated that although the course administrator is usually responsible for designing online teaching materials and making them available for students in a friendly format during synchronous classes, teachers should consider the fact that some students will not be able to access these materials for different reasons. In addition, some teachers may not be trained to handle students' digital privacy which requires keeping the students' online information and communication protected (Al Damen, 2020, Khlaif \& Salha, 2020).

In Mahyoob (2020) study, which was introduced above, the findings revealed that the students' online experience during COVID19 was greatly influenced by using technical tools. For example, although nearly $70 \%$ of the participants were able to complete the required activities and assignments, only less than $8 \%$ of students reported being able to attend classes and participate actively in the class. Other challenges related to technology according to Noor (2020) were the unavailability of proper devices, high prices of internet quota and low digital literacy. Some students showed frustration when they had to free up space on their mobile phones to install new apps required for their classes and buy new internet data plans which made students perceive online classes as "challenging" (Agung, 2020). Melvina et al. (2020) concluded in their study, which was done among 6 undergraduate EFL learners in Indonesia, that the students believed in the implementation of distance learning during the COVID-19 pandemic and viewed it as the best option available. However, they stated that the financial and technical issues are their prominent concerns in distance learning. This conclusion has been made by many recent studies on distance learning during the COVID-19 pandemic (Hapsari, 2021; Mahyoob, 2020; Agung, 2020; Kaisara \& Bwalya, 2021).

In addition, students reported that their academic progress was affected during virtual learning (Mahyoob, 2020). Students stated that they did not achieve the expected improvement in their English proficiency as some had difficulties related to learning English skills such as writing, speaking and reading. These challenges resulted in a general dissatisfaction among students towards the online learning experience. This dissatisfaction can also be linked to the reported low level of interaction between students and their teachers during the online classes. Al Damen's study conducted in 2020 at the CPS during the ERT involving 8 teachers and 80 SQU students in the foundation program revealed that instructors found teaching writing the most challenging, followed by teaching listening skills while reading was not problematic during ERT. This could be because most of the reading activities were students-paced and were required to be done asynchronously. One the other hand, students chose the listening skill as the most difficult skill to learn during ERT followed by writing. Unsurprisingly, reading was the least difficult to learn. According to Al Damen (2020), writing was not the most challenging skill because the teachers spent efforts explaining and providing necessary assistance for their students because the teachers found teaching it challenging online. This resulted in focusing primarily on teaching this skill compared to the other skills. Also, teachers reported that it was not easy for them to monitor students' progress in listening during ERT which might have resulted in students finding it the most challenging.

Similarly, Rifiyanti (2020) surveyed 108 undergraduate English students in an Indonesian Institute and found that listening is the most difficult skill for students to learn online (36\%). The second most difficult is speaking (33\%) followed by writing (17\%). Students selected reading as the least difficult skill to learn in an online class (14\%).

Hapsari (2021) investigated the anxiety level among English learners in an Indonesian higher institution during the COVID-19 outbreak. Findings showed that students were more anxious at the first stage of shifting to distance education compared to a year after the shift. However, students' anxiety levels continued to be triggered by unstable internet connectivity, not receiving adequate feedback from the teacher, not being able to download materials or complete assignments because of various technical issues and sometimes missing important information during the class because of device malfunction. Students also reported feeling isolated because of the lack of face-to-face interaction during online learning experience. In addition, students felt anxious and stressed as a result of the COVID-19 pandemic (Mahyoob, 2020; Heng \& Sol, 2020). Another source of stress found in Agunus's study (2020) was not having enough time to complete given assignments. Findings showed that $66.7 \%$ of the 
participants were not enthusiastic about their online classes despite the high level of participation (94\%). This was due to the "marathon assignments" given to them. 57\% of the students in the study described online assignments as "heavy and stressful". Another obstacle which students encountered while receiving online education was the home environment that was described by students as noisy (Kaisara \& Bwalya, 2021).

It can be seen that although e-learning during COVID-19 has its advantages, it is also accompanied by major obstacles related to technology, assignments' load and emotional stress.

\subsection{Solutions}

The COVID-19 crisis has been considered as a "silver lining "and the "catalyst" for the educational system worldwide (Heng, 2020 \& Zhao, 2020). Zhao (2020) believed that this disruption in the educational system might inspire leaders to reimagine online learning by viewing it as a different way of learning rather than a subordinate version of face-to-face learning (Zhao, 2020). The below solutions have been proposed by different researchers to rethink online learning and make it more effective for teachers and students alike.

Hapsari (2021) stated that although students showed a positive attitude to study online, which may come from their personal desire to improve their knowledge and skills, they felt anxious because of several factors such as not being ready for the online experience, lack of collaborative work during the class and technical issues that disturbed the flow of their learning. Therefore, if the effect of these factors is minimized, the online learning experience would be more efficient for students.

In his article, Martin (2020) introduced a five-point guide for educators to optimize the virtual learning process during COVID-19. He started by advising educators to make their instruction as clear and organized as possible since monitoring students' understanding is challenging during online teaching. This will prevent introducing too much information to students that is likely to be overwhelming at the beginning of the semester. The second point to consider is presenting the content in a way suitable to the students' level of knowledge and skills. The process of material selection should be monitored and materials are introduced in a doable manner which minimizes students' confusion at early stages of their learning. The third point highlighted by Martin is motivation during the online learning experience. He identifies self-regulation as the major feature that contributes to students' motivation to learn. This is because a lot of distractions in the online environment may cause students to go off track, so it is important for students to be well-organized and focused during online learning. He suggests giving students some printable tasks they can do offline; the required work can be broken into small units with frequent deadlines to enable students to get teachers feedback more frequently. The fourth aspect to be considered according to Martin's guide to optimize online learning during Covid-19 is maintaining efficient interpersonal relationships to promote learning. Martin suggests that students always find a way to communicate with each other; therefore; more effort is needed from the teachers' side to establish successful teacher-student relationships during online experience. Teachers are advised to use different communication tools to maintain an effective yet professional relationship with their students. This can only be done by communicating with students through three channels. The interpersonal channel is to support students emotionally; the content channel is to deliver interesting and suitable content to students and finally the instruction channel prevents students from being overwhelmed by loads of instructions. Mental health is the final point to consider in Martin's guide - which represents the most important one from the researchers' point of view. In his article, Martin advises to look at mental health as a means for successful learning instead of a desired outcome since poor mental health will definitely affect learning. It is relatively easier to identify students with mental health problems during face-to-face instruction than during online interaction. Martin highlights the importance of providing students with contact if they are emotionally struggling. During the Covid-19 outbreak, it is expected that more students will have to deal with illness or death in the family. They will likely need support to face their anxiety during this difficult time.

Dhawan (2020) proposed some suggestions to enhance the effectiveness of online learning during the pandemic. Her suggestions include ways to improve interaction and collaboration through humanizing the learning process. She suggested making the learning environment more interesting, dynamic and interactive, creating forums for communication using social media and other virtual platforms and promoting collaborative and project-based learning.

Leng et al. (2020) proposed several recommendations to take forward online learning and teaching in Cambodian higher education institutions, which can be applicable to many countries where use of distance learning is still in its early stages. Their recommendations involve six aspects:

1. Leadership: Institutional leaders should invest in blended learning by providing necessary facilities and resources to support the digital transformation. 
2. Digital infrastructure and literacy: Higher education institutions should build smart classrooms and learning management systems such as Moodle and Google Classroom. They should also provide a stable internet connection, support students with low income and improve digital literacy of teachers and students.

3. Pedagogy: It is important to provide training programs for teachers to ensure that they will be able to adopt the right teaching and assessment methods that suit the offered teaching tools. The researchers suggested assessment methods such as case studies, pop quizzes, information packages, discussion forums and presentations.

4. Support for students and faculty members: Students and faculty members are affected by the pandemic, and it is likely that they are dealing with family commitments and feelings of loneliness and disconnection. Thus, it is recommended that the student affairs office provide orientation programs for students on how to deal with the "new normal" learning environment. An e-community of students and staff that include activities and schedules should be developed to maintain online social interactions.

5. Attitude to teaching and learning: Students should be trained to be independent thinkers and lifelong learners. Each educational institution should instill a culture of reading, discussion and debate among students that supports their personnel and professional growth. Teachers should also be open to changes and ready to adjust their teaching methods.

6. Government support: The government should provide financial support to establish a proper digital infrastructure and should also establish a nationwide training programs for academic and non-academic staff to facilitate crossinstitutional communication and encourage exchange of expertise between higher education institutions.

Fung et al. (2020) highlighted the importance of building up student-teacher interaction to enhance online learning. They suggested that teachers start their online classes early and use the chat function to run "regular checkpoints" to check up on students. Another suggestion was to boost their engagement's level by using real-time responses. This can be done through using interactive platforms such as Mentimeter, Padlet, Kahoot, Poll Everywhere and Pigeonhole Live.

\section{Methodology}

\subsection{Participants}

The total number of participants who completed the questionnaire is 155 students. Figure 1 gives a summary of the participants' demographic information.

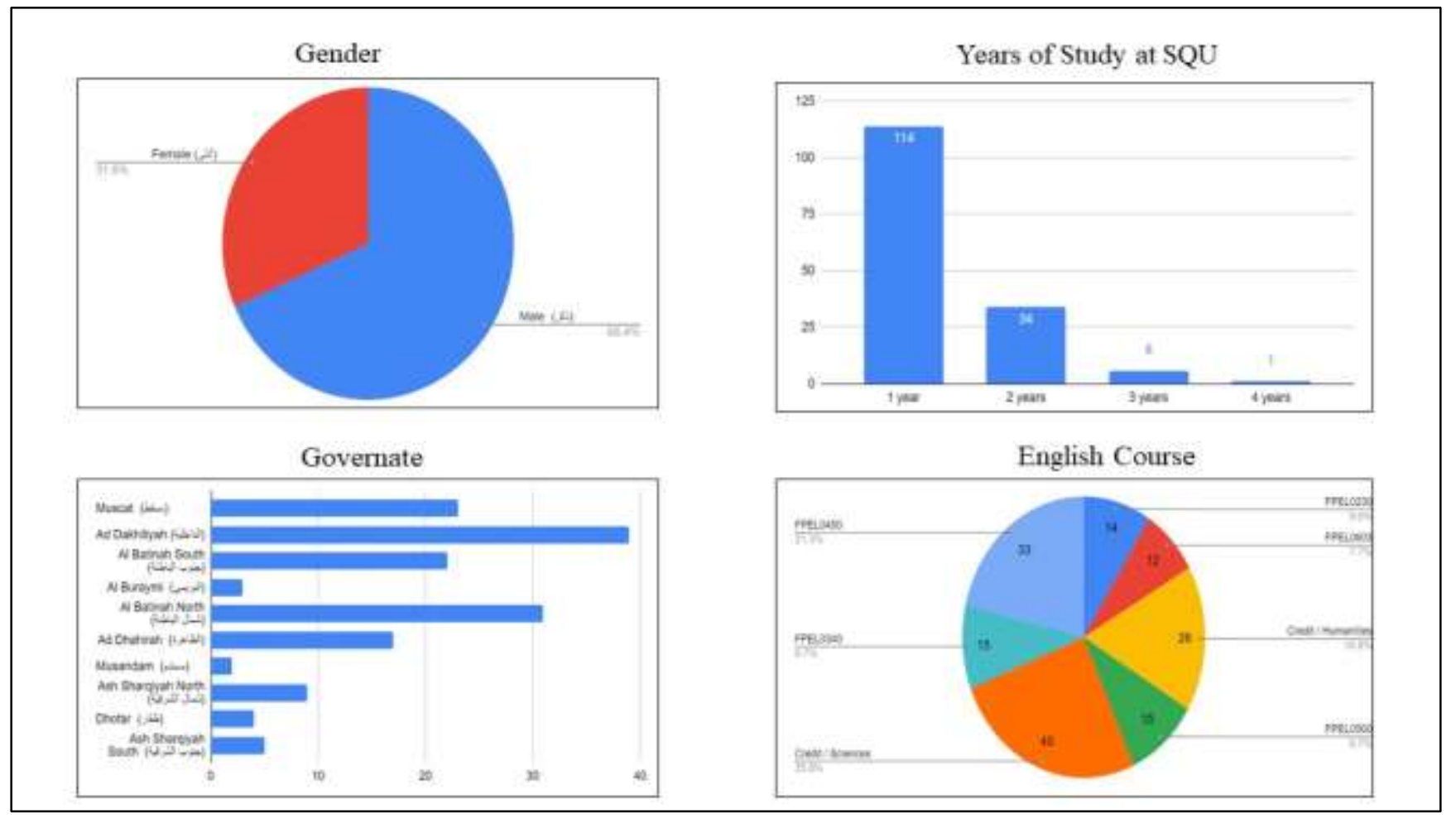

Figure 1: Participants demographic information

As it can be seen from the charts, the sample included 155 students enrolled in the credit courses (66) and foundation program (89). Also, the questionnaire was completed by both male (106) and female (49) students. In addition, most of the research 
sample were freshmen (73.5\%) besides sophomores (21.9\%), third year (3.9\%) and only one student in his fourth year of study. Therefore, findings might be mostly indicative of $1^{\text {st }}$ year students' opinion who did not get the chance to have an orientation week or experience university life. The 155 students came from the 10 different regions of the Sultanate. The majority were from Al Dhakhliya and Al Batinah North while only 3 students came from Al Buraimi and 2 from Masandam. Such distribution is reasonable as it relatively represents the size of the students' population from each region.

\subsection{Research instrument}

This study adopted a quantitative method of data collection. An online anonymous questionnaire designed in Google Form was sent to teachers in the English foundation program as well as those in the credit courses (humanities and sciences) offered by the Center for Preparatory Studies (CPS) in Spring 2021. The teachers were asked to forward the three-part questionnaire to their students. It started with a section on the participants' demographic information, followed by a section on aspects of online learning and it ended with the participants' general attitudes towards online learning. A Likert scale (Always, Usually, Sometimes, Rarely, Never) was used to elicit the students' views on connectivity, the first aspect under this part. However, another Likert scale (Strongly Disagree, Disagree, Neutral, Agree, Strongly Agree) was developed to collect participants' attitudes towards the remaining four aspects related to their experience of online learning. There was also an open-ended question after each aspect to allow students to add any thoughts or ideas they wanted to share with the researchers with regard to each topic. Students' comments added in Arabic in the questionnaire were translated into English by the researchers. The questionnaire was available for students for the last three weeks of the Spring 2021 semester.

\section{Results and Discussion}

\subsection{Connectivity}

As shown in Figure 2, when asked how frequently they used WiFi to attend classes, almost $60 \%$ of participants reported that they always connected to WiFi to attend online classes while the frequency varied among the remaining students who usually (25.8\%) or sometimes (7.7\%) used WiFi to attend class. A total of almost $7 \%$ of participants indicated that they rarely or never used WiFi to attend their classes online. This result was consistent with the students' responses to the second question under this aspect which was 'I use my mobile data to attend my English classes' as only $7.7 \%$ reported that they always used their mobile data to attend their classes online. This means that the majority of students had access to the internet, whether through WiFi or mobile data. However, only $5 \%$ of students reported that the internet connection was always good and stable (question three). This shows that the remaining (95\%) of the research sample had issues with the internet at some point of their study.

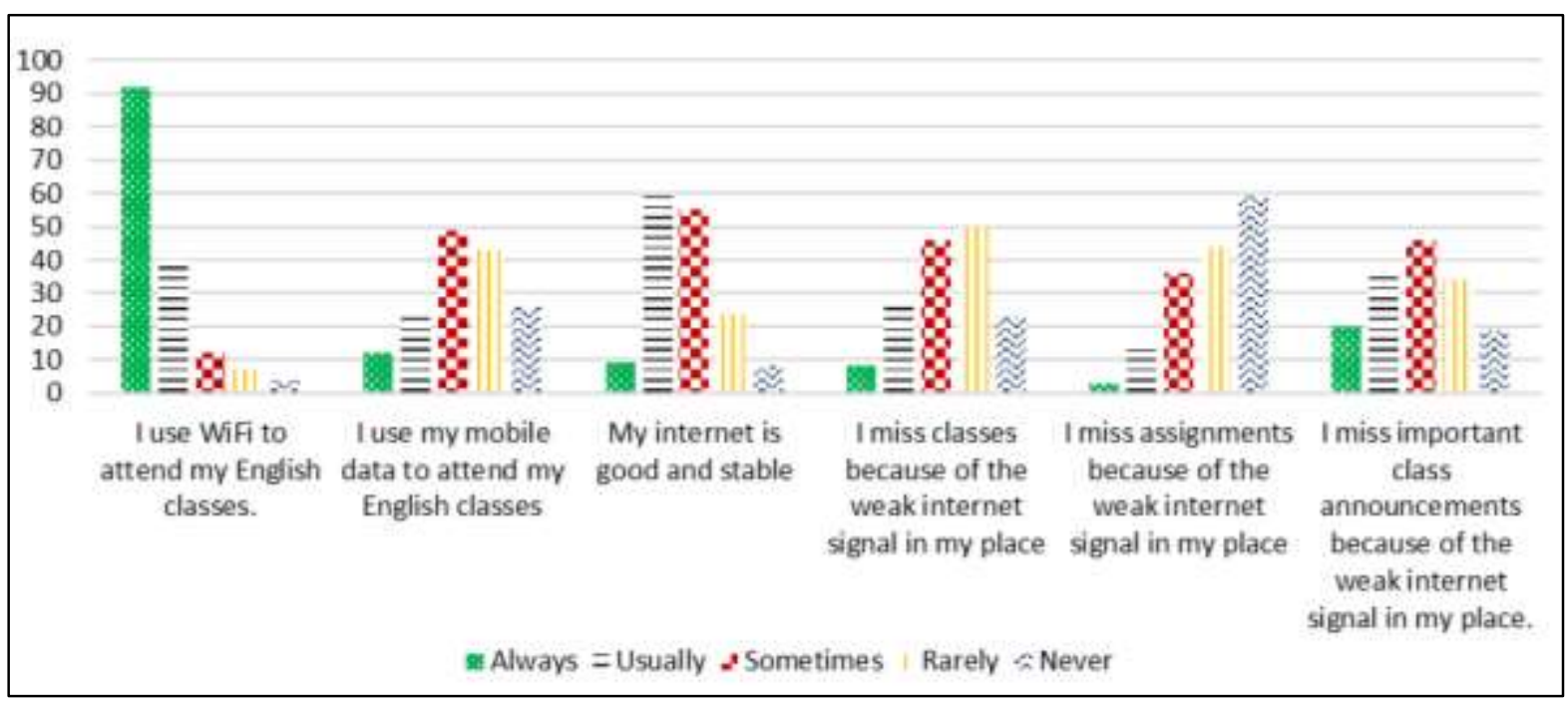

Figure 2: Students' responses to connectivity

The last three questions under connectivity aimed to explore the effect of connectivity on the students' attendance, homework and assignments submission and missing important announcements in the classroom. Only 24 students (14.8\%) of the sample stated that they never missed classes because of issues related to the network, whereas almost $85 \%$ of students had missed classes because of the 'bad' network. Likewise, almost $90 \%$ of the participants said that they missed important class announcements because of connectivity. Interestingly, although the questionnaire revealed that about $60 \%$ of the respondents had issues submitting their assignments and homework due to connectivity problems, this percentage shows that the impact of the weak network was less on the tasks that can be done outside the class time. Some students expressed their frustration with 
the network in their area in the open-ended question following the connectivity section. Some of the statements are listed in Table 1.

Table 1: Students' Comments on Connectivity

\begin{tabular}{|l|}
\hline Connectivity \\
\hline Internet is good but I need money to connect \\
\hline The network not good/very bad \\
\hline I am kicked out of the online class because of the weak connectivity \\
\hline I can't attend because the internet is very weak/slow \\
\hline The teacher's voice is not clear because of the weak network. \\
\hline I have to leave the house to find a good network connection. \\
\hline During exams, it takes me too long to navigate between pages because the network is slow. \\
\hline I live in a rural area, so the network is not stable. \\
\hline I can't concentrate in the class because of the bad network. \\
\hline
\end{tabular}

It can be concluded from the students' feedback on connectivity that having access to a network, mainly through WiFi, does not necessarily mean that the students will receive a quality learning experience. This is due to the fact that the majority of students did not have a stable internet connection which caused financial and academic challenges. According to students' comments, some were kicked out of live classes, missed important information in the class, missed some classes and had to leave the house to join live lessons because of bad connectivity. All this could have contributed to making synchronous classes stressful for students considering the fact that synchronous classes were a whole new experience at SQU.

\subsection{Communication with teachers and classmates}

The aim of the statements under this section in the questionnaire was to understand the communication level between students and their teachers as well as the students and their classmates during online classes. According to Figure 3, almost $80 \%$ of the students reported that their teachers were available when they needed them compared to about $6 \%$ who disagreed with this statement. However, when asked whether the teachers showed understanding when the students faced technical problems, the percentage of students who disagreed with this statement doubled (nearly 13\%) while 69\% agreed that their teachers were understanding of the technical problems which the students encountered during online courses. Students mentioned in the open-ended section that teachers did not count the technical issues they encountered during the course as valid excuses. This finding, hence, stresses the importance of raising teachers' awareness about virtual equity, as advised by Khlaif and Salha (2020). The findings of our study showed that nearly $95 \%$ of the research sample had connectivity issues at some point during their online learning which reflects the struggle students go through during online learning. However, this finding is reported from the students' point of view. Therefore, it would have been enlightening to explore teachers' perceptions on accepting connectivity failure as valid excuses for missing classes or late submissions.

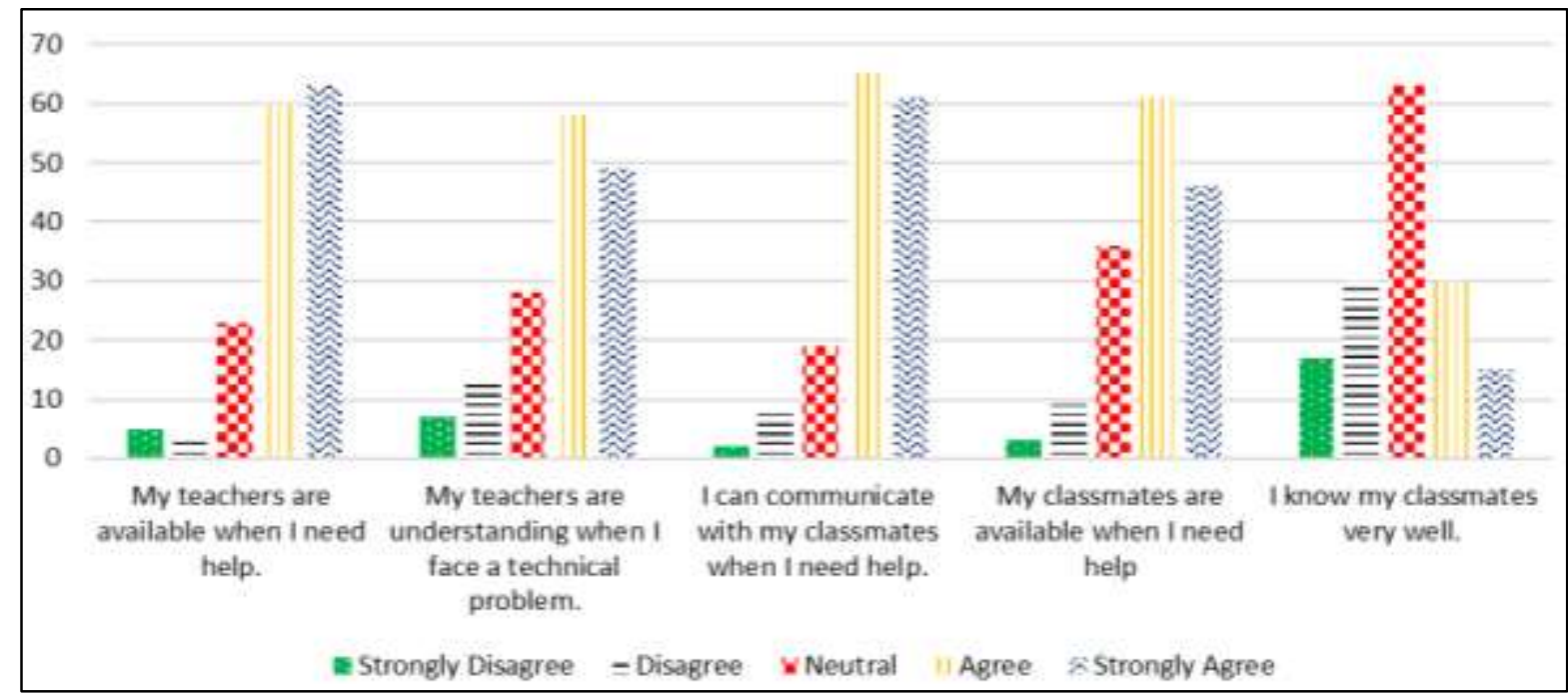

Figure 3: Students' responses to communication 
There were similar findings when students were asked whether they could communicate with their classmates (81\% agreed, $6.5 \%$ disagreed). Only $69 \%$ of the participants said that their friends were available when they needed help while around $8 \%$ disagreed with this statement. The students' responses to the last statement in this section wereinteresting. The percentage of students who agreed and disagreed with the statement (I know my classmates very well) was almost equal (30\%) while the percentage of students who chose neutral as their response was $40 \%$. It was found that the statement 'I know my classmate very well' might have been vague to students. It could have been interpreted in different ways and there might have been a need for follow-up statements to clarify it or an open-ended question for students to elaborate more on how well they knew their classmates. alternatively, the statement could have been reworded to 'I have established a good rapport with my classmates'. However, the findings of the statement in the questionnaire can still be indicative of students' opinions on how well they knew their classmates.

Further analysis of the students' responses to the last statement 'I know my classmates very well' showed that only $18 \%$ of the female population thought that they knew their classmates very well compared to $34 \%$ of the male population (Table 2). These findings were consistent with the percentages of students who disagreed with the same statement as more students from the female population reposted that they didn't know their classmates very well compared with $27 \%$ of the male students.

Table 2: Gender responses to 'I know my classmates very well'

\begin{tabular}{|l|l|l|l|l|l|l|}
\hline Participants & Agree & $\%$ & Disagree & $\%$ & Neutral & $\%$ \\
\hline Female (49) & 9 & $18.4 \%$ & 18 & $36.7 \%$ & 17 & $34.7 \%$ \\
\hline Male (106) & 36 & $34.0 \%$ & 29 & $27.4 \%$ & 46 & $43.4 \%$ \\
\hline Total (155) & 45 & $29.0 \%$ & 47 & $30.3 \%$ & 63 & $40.6 \%$ \\
\hline
\end{tabular}

Students' positive and negative comments left in the open-ended question at the end of this section in the questionnaire are summarized in Table 3.

Table 3: Students' Comments on Communication with Teachers and Students

\begin{tabular}{|l|}
\hline Communication \\
\hline Positive comments \\
\hline We could communicate via WhatsApp which was great. \\
\hline The teachers give their phone number to communicate with them. \\
\hline They are very helpful. \\
\hline Teachers are there when we need them. \\
\hline Teachers and students are cooperative. \\
\hline Negative comments \\
\hline $\begin{array}{l}\text { Not all students are helpful. When I miss something in the class and ask students in the group I have to wait for the } \\
\text { same students who always help although the rest of students know the answer. }\end{array}$ \\
\hline Teachers do not consider network problems as an excuse. \\
\hline
\end{tabular}

Overall, it seems that students found their teachers and classmates helpful and cooperative during the online learning experience. Nevertheless, some frustration was shown in the open-ended section stating that the classmates were not very helpful when seeking their help as only certain students from the class would always offer help while the others wouldn't. This means that creating a channel of communication among students doesn't always mean that communication will occur. This might have happened because students did not know each other in person anddid not build a rapport during online instructions which made them care less about helping each other. On the other hand, students liked the use of WhatsApp as a way of communication and one student liked having the instructor's phone number to communicate with him/her. This outcome agrees with the existing literature showing that WhatsApp is one of the most favourable means of communication during COVID-19 (Mahyoob, 2020; Agung, 2020; Asmara, 2020). The next section presents the findings related to the third aspect of online learning which investigates students' views on the learning environment and learning experience. 


\section{3 learning environment \& learning experience}

There were two statements on the learning environment under this section. The first asked students to share their views on whether the home environment was conducive to online language learning and the second one was about distractions during the online class if any. Figure 4 demonstrates that the percentage of students who thought that the home environment contributed to learning English was slightly higher than those who shared the opposite view (about 33\%, 30\% respectively). A higher percentage of students took a neutral stand towards this statement (almost 37\%). In addition, more students indicated having distractions during online classes (45\%) compared to the students who didn't (27\%). The rest of students (27.7\%) chose neutral as their responses. It was noted that about $30 \%$ of students took a neutral stand when asked to reflect on their home environment. This could be attributed to students feeling uncomfortable talking about their home and family support during virtual learning.

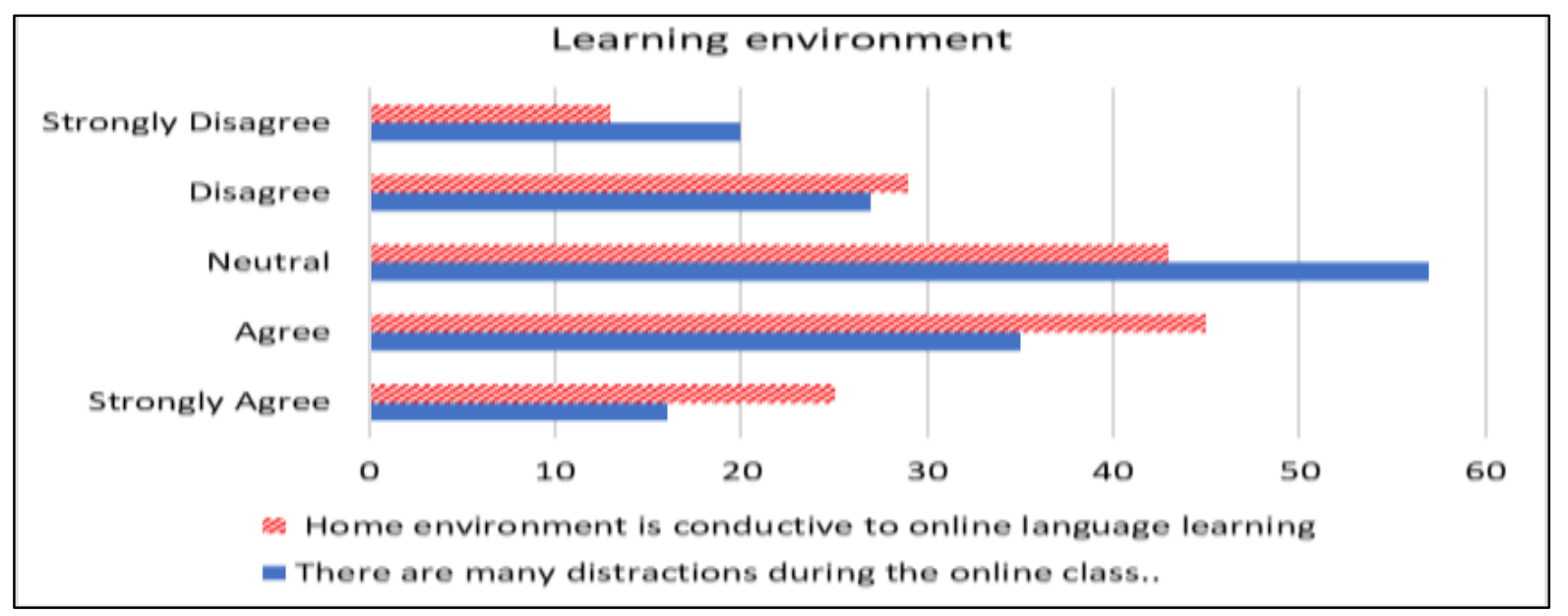

Figure 4: Students' responses to learning environment

Moreover, about $60 \%$ of the students were satisfied with the duration of online classes in comparison to about $17 \%$ who weren't. Only about $24 \%$ of the respondents thought that the amount of online homework and assignments was reasonable while nearly half of the students thought that load of work was unreasonable. Similar findings were revealed in the literature showing that students found that the online instruction was not as problematic as the overwhelming load of requirements with insufficient time to complete them (Agunus, 2020). Finally, half of the research sample thought that their level of English had improved while only $10 \%$ didn't witness improvement in their English. A significant percentage of students (30\%) was neutral to this subject.

The last question under this aspect was asking students to order the four English skills from the most challenging to learn during online instruction to the least challenging. Table 4 summarizes the students' responses.

Table 4: The Most Challenging English Skill to Study Online

\begin{tabular}{|c|c|c|c|c|c|c|c|c|}
\hline \multirow[b]{2}{*}{ Skill } & \multicolumn{2}{|c|}{ Most challenging } & \multicolumn{2}{|c|}{ Challenging } & \multicolumn{2}{|c|}{$\begin{array}{l}\text { Somewhat } \\
\text { challenging }\end{array}$} & \multicolumn{2}{|c|}{$\begin{array}{c}\text { Least } \\
\text { challenging }\end{array}$} \\
\hline & $\begin{array}{c}\text { number } \\
\text { of } \\
\text { students }\end{array}$ & $\%$ & $\begin{array}{c}\text { number } \\
\text { of } \\
\text { students }\end{array}$ & $\%$ & $\begin{array}{c}\text { number } \\
\text { of } \\
\text { students }\end{array}$ & $\%$ & $\begin{array}{c}\text { number } \\
\text { of } \\
\text { students }\end{array}$ & $\%$ \\
\hline Reading & 22 & $14.2 \%$ & 33 & $21.3 \%$ & 38 & $24.5 \%$ & 62 & $40.0 \%$ \\
\hline Writing & 55 & $35.5 \%$ & 43 & $27.7 \%$ & 41 & $26.5 \%$ & 16 & $10.3 \%$ \\
\hline Listening & 30 & $19.4 \%$ & 44 & $28.4 \%$ & 45 & $29.0 \%$ & 36 & $23.2 \%$ \\
\hline Speaking & 48 & $31.0 \%$ & 35 & $22.6 \%$ & 31 & $20.0 \%$ & 41 & $26.5 \%$ \\
\hline
\end{tabular}

Table 4 shows that the participants chose writing to be the most challenging skill to learn during online learning while reading skill was the students' choice as the least challenging. Due to the demanding nature of the writing courses at CPS, students' perception towards writing to be the most challenging was not unexpected. In fact, teachers at CPS chose writing as the most challenging skill to teach as it required communicating loads of information to students and finding effective ways to give them feedback (Al Damen, 2020). On the other hand, reading was also reported to be the least challenging for students during distance learning in other studies (Rifiyanti, 2020; Al Damen, 2020). The researchers justify this finding to the nature of reading 
tasks students were asked to complete during online learning. The least challenging does not necessarily mean the least difficult, rather it could mean that learning this skill online means less confrontation with the teacher, more flexibility regarding the time given to complete the reading activities as they were mainly done asynchronously. Students are able to check difficult words from a dictionary when the camera is off. In Al Damen (2020), teachers reported that they did not feel that they taught reading skills at all during ERT, nor did they think that their students did the reading tasks on their own. The students didn't leave many comments in the open-ended space at the end of this section. Table 5 has a summary of their comments.

Table 5: Students' Comments on Learning Experience \& Learning Environment

\begin{tabular}{|l|}
\hline Learning Experience \& Learning Environment \\
\hline $\begin{array}{l}\text { The doctor should give the student } 1 \text { assignment in the week because some student has } 5 \text { (mature?) so they don't } \\
\text { have time }\end{array}$ \\
\hline We need to go back to face-to-face classes \\
\hline Be easy and fair. \\
\hline Study environment is not suitable because there are a lot of distractions at home. \\
\hline
\end{tabular}

It is evident from the students' comments that they had concerns about the load of assignments, being treated fairly by their teachers and having a suitable study environment at home. Identity and Assessment will be discussed next.

\subsection{Identity}

Figure 5 shows students' responses to 10 statements related to their identity online. The first three statements were about using cameras in the online classes. The majority of students reported that they preferred to attend classes with the camera switched off. They stated that they were doing so because their classmates switched their cameras off as well.

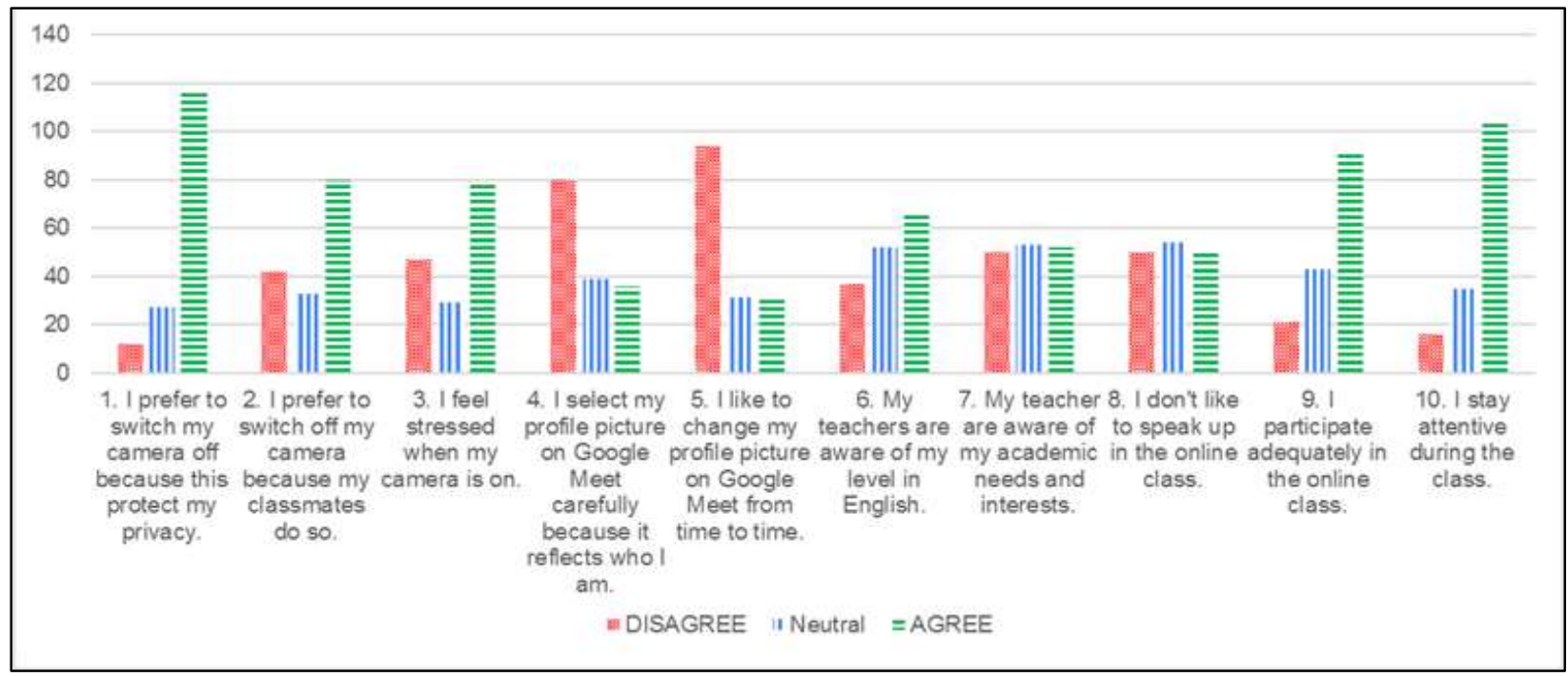

Figure 5: Students' responses to identity

Moreover, the number of students who felt stressed when attending their online classes with the camera switched on was double the ones who didn't. Similarly, it is obvious from the findings that switching off the cameras helps students reduce their levels of stress (statements 2\&3). The act of students switching their cameras off achieved anonymity which is a positive aspect students find in online learning (Al Hosni, 2013). Al Hosni (2013) stated a positive correlation between anonymity and students' participation in online classes as students felt less stressed about making mistakes when they are anonymous to their classmates. In this study, the majority of students preferred to switch the camera off to protect their privacy and the majority reported being active and attentive during the online class.

The fourth and fifth statements were about the students' profile photos which their classmates and teachers could see online. The majority of the research sample indicated that they didn't spend time choosing their profile photos nor did they care to 
change it from time to time. This finding could be a result of students' anonymity and the fact that they did not know each other as they would do in face-to-face mode of communication. Also, changing their profile photo did not seem a priority considering the findings of this study which showed that students were more concerned about getting a reliable connection and submitting work on time.

The next two statements asked students to reflect on teachers' awareness about their level of English and academic needs. Although more students felt that their teachers were aware of their real level of English, there were no significant differences among the percentages of students who disagreed, were neutral or agreed with the statement 'My teachers are aware of my academic needs and interests.' The insignificant differences in the percentages could be attributed to the fact that students thought that their teachers would know their level of English by the time the questionnaire was sent (end of the semester); yet they wouldn't be in a place to decide whether their teachers would know their interests.

Similar results were found when analyzing the research sample input on whether they liked to speak up in the classroom or not as there was an insignificant difference between the three options. However, a high number of students confirmed their adequate participation and their attentiveness in the online classroom. Although this finding might appear to be contradicting with the fact that students disliked speaking in the class, this could also mean that there were other means of participation besides speaking up which were encouraged during the online class like using the chat, raising hand features and doing live interactive exercises during class time.

\subsection{Assessment}

The last aspect under the second part of the questionnaire was assessment. It was observed that the percentage of students who found the number of quizzes and other assignments adequate (42.5\%) was slightly higher than those who didn't share the same view (32\%). However, about half of the research sample (47\%) thought that they were not given enough time to complete the required quizzes and assignments compared to the ones who thought that the time was adequate (26\%). However, there was a significant difference between the percentage of students who thought that they had received sufficient feedback from their teachers in comparison with the students who felt that the teachers' feedback was insufficient. The percentage of the students who were satisfied with their teachers' feedback was almost $80 \%$ compared to nearly $8 \%$ in the unsatisfied group. These percentages are similar to the ones reported in Al Damen's (2020) study when students were asked to evaluate the effectiveness of the methods used by their teachers in the foundation program to give them electronic feedback during ERT. Only 3.8\% felt that the methods were not effective, while $75 \%$ thought that feedback via WhatsApp and Remind were the most effective.

\subsection{General attitudes}

In this part, participants were asked in the first 2 items to indicate their level of motivation and attention during online English language classes. On a continuum from 1 to 5 , around half of the participants $(46.5 \%)$ believed that they were fairly motivated and around $35 \%$ were highly motivated (Figure 6 ). Only $18 \%$ of the participants described themselves as least motivated during the online English classes. These findings agree with the literature that shows a generally positive attitude towards online learning (Agung,2020; Erarslan \& Topkaya, 2017; Hapsari 2021; Mahyoob, 2020). This could be also attributed to having a fairly good relationship with their teachers and classmates, as indicated in earlier findings. Students found their teachers and peers helpful and they believed they received constant and sufficient feedback from their teachers.

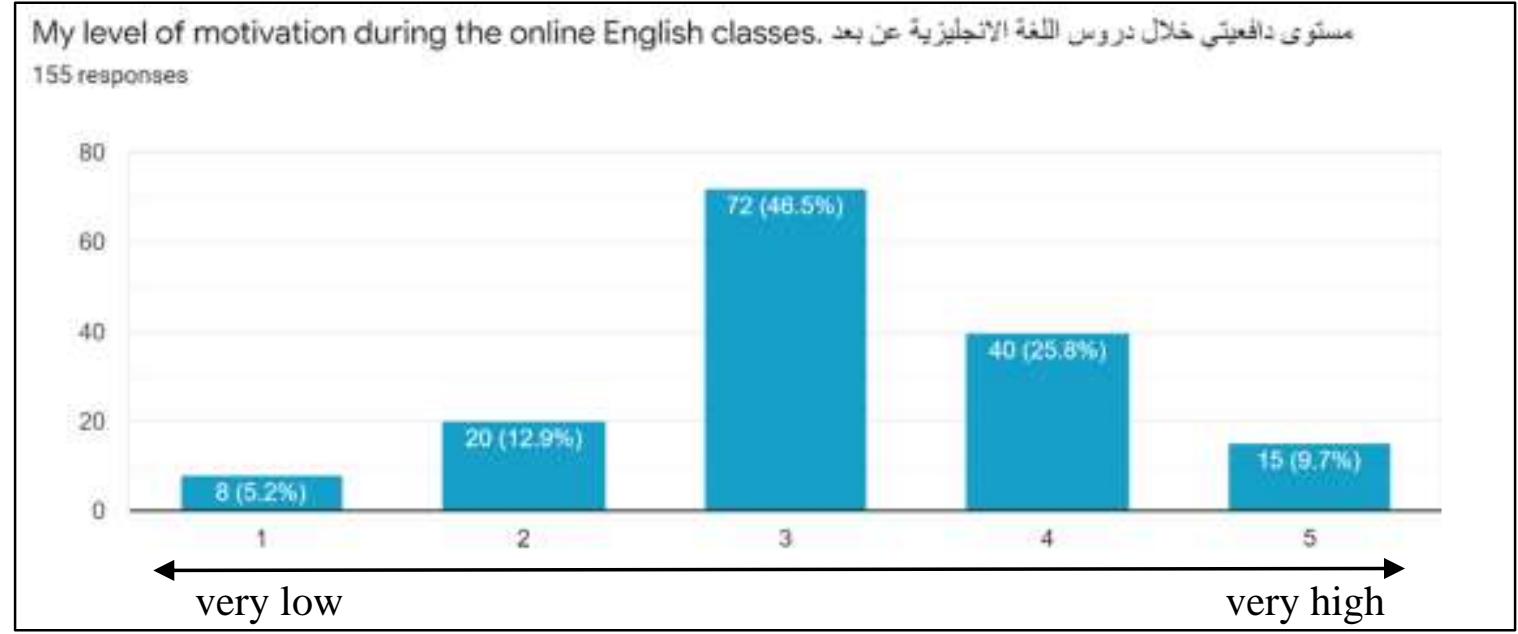

Figure 6: Students' motivation 
With regard to the level of attention during the class, Figure 7 shows that $60.6 \%$ of the participants believed that they were highly attentive $(4 \& 5)$ during class which agreed with the finding in item 10 under the identity part. 13\% of the participants were the least attentive. Unsurprisingly, this percentage relatively corresponds with the percentage of the least motivated students.

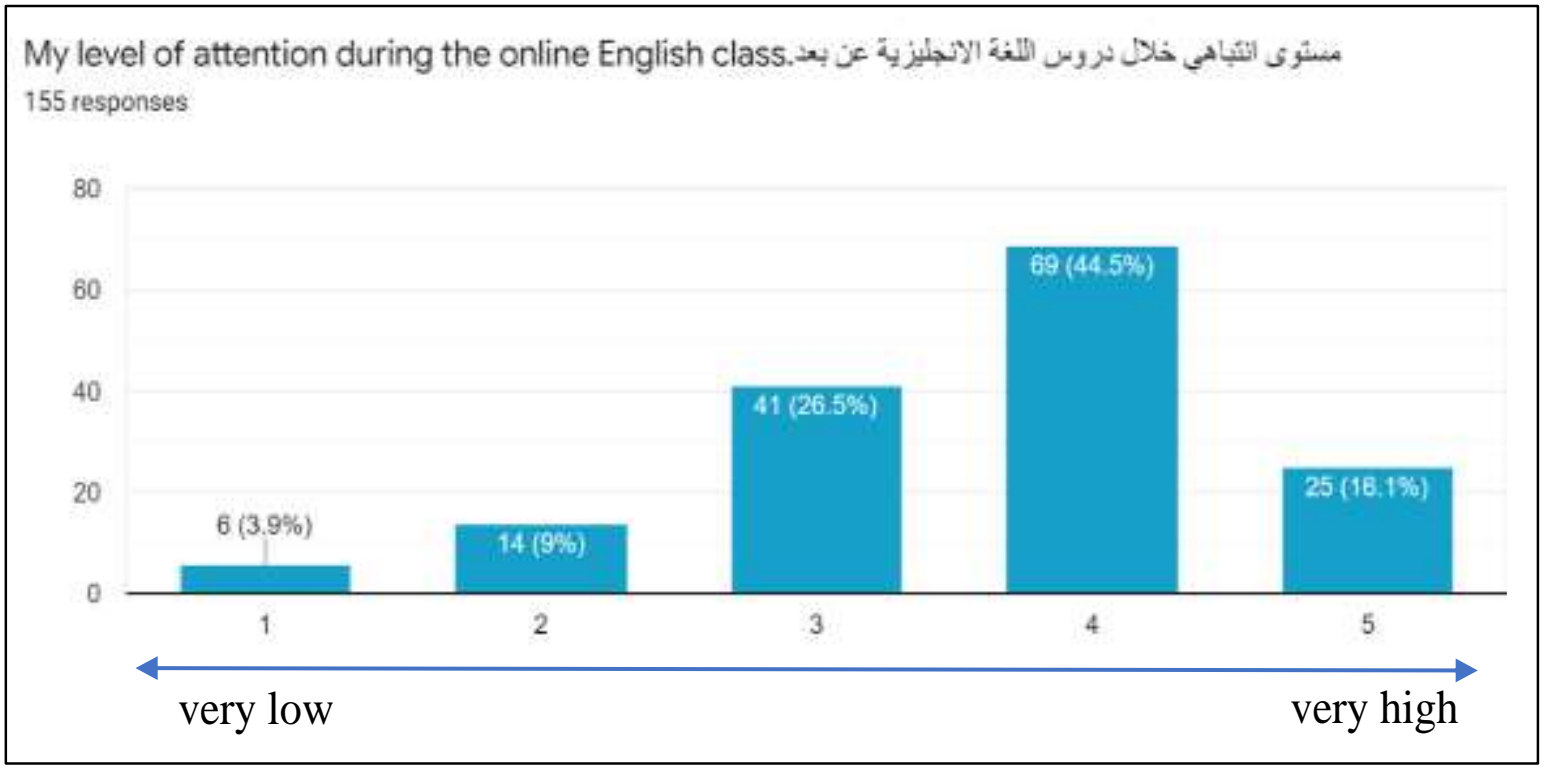

Figure 7: Students' attention

The last two items on the questionnaire asked participants to evaluate their overall learning experience in the online English classes. The bar chart in Figure 8 summarizes the participants' responses on how positive they found their learning experience. $36.8 \%$ of the participants found it fairly positive with $42 \%$ of them finding it highly positive. Only $21 \%$ thought their online English classes were a negative experience.

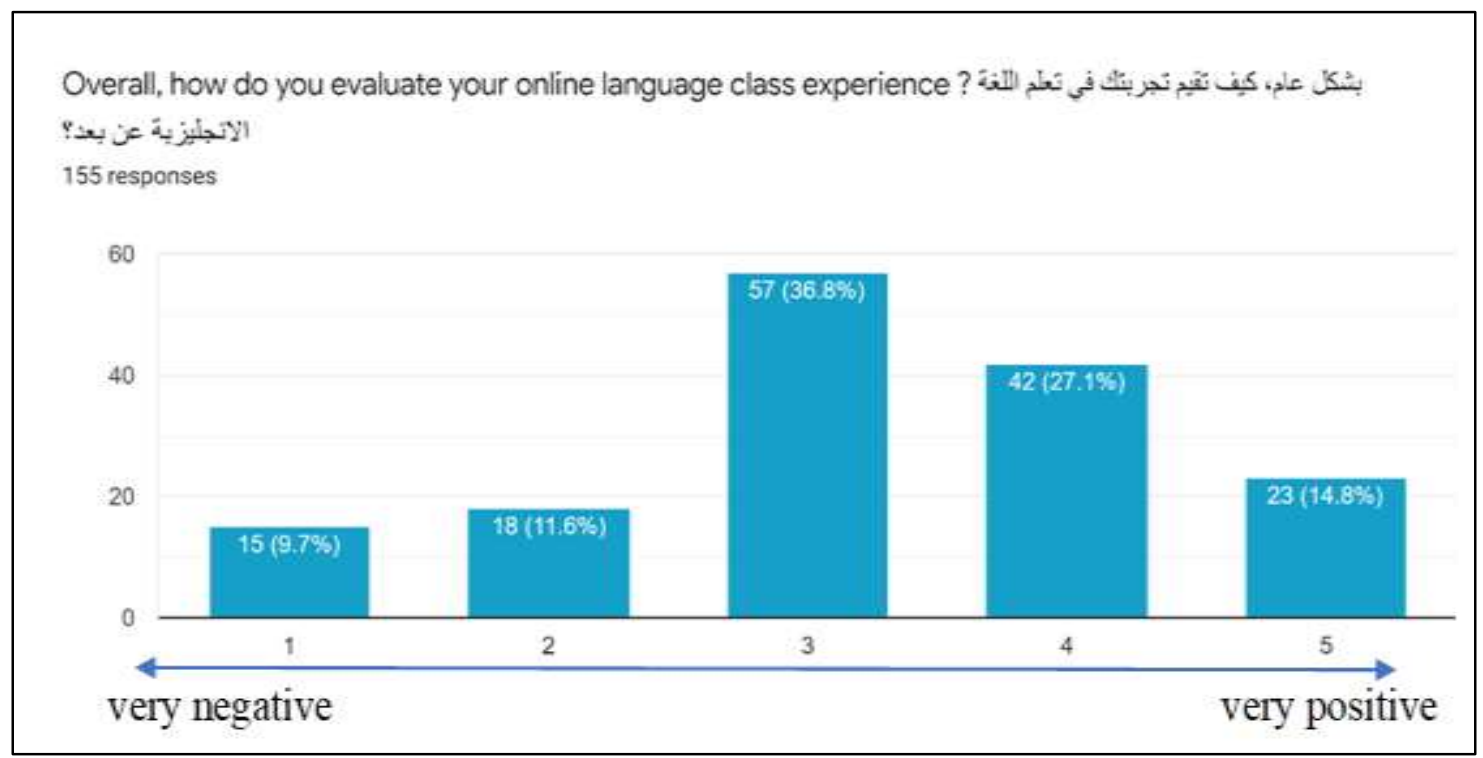

Figure 8: Perspectives on online language classes

The last question was on how relaxing/ stressful your learning experience in online language classes was. According to Figure 9, in total, around $29 \%$ found the experience fairly relaxing and $44 \%$ found it highly relaxing. $27 \%$ of the participants found it a stressful experience. These results indicate that half of the participants experienced levels of stress at some point in their online studies. 


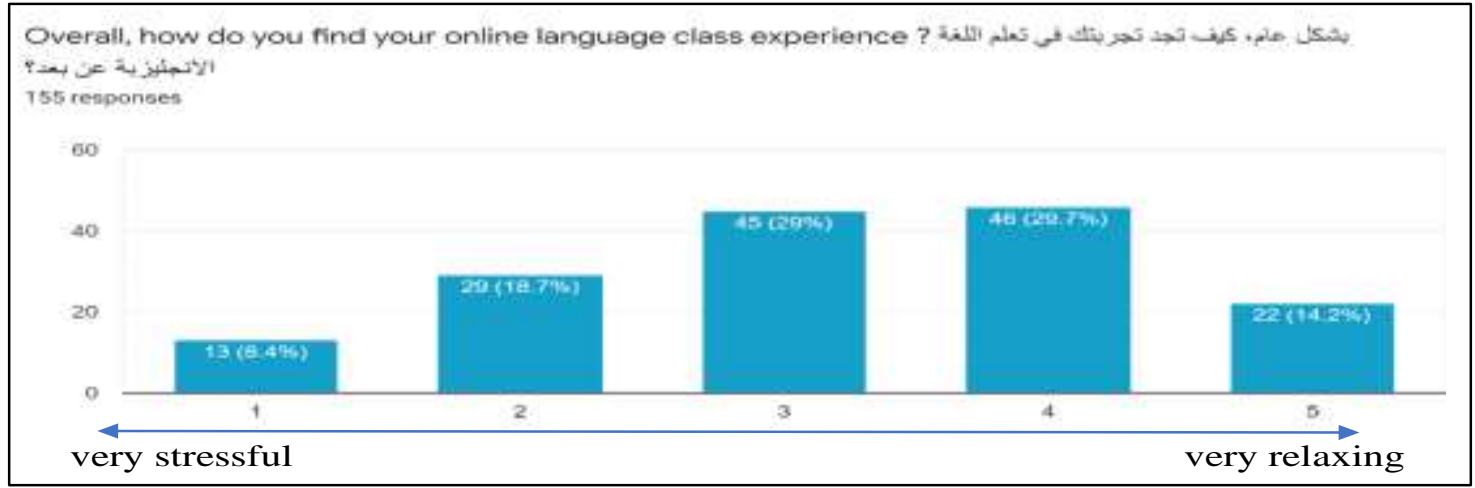

Figure 9: Stress level during online language classes

\section{Conclusion}

The findings of this study are in concordance with the existing literature. They support the notion that distance learning is generally a positive experience among English language learners and it can be enhanced through providing the necessary technical and pedagogical support. The participants of this study revealed a positive attitude towards online EFL classes, had the necessary digital skills and a good level of motivation to learn online. They also believed that their teachers and classmates were helpful and that they received adequate feedback from their teachers on their academic progress. However, technical and financial barriers related mainly to connectivity issues were expressed by the participants. It is believed that connectivity issues and the challenges they entail may affect students' level of motivation and increase their stress levels which, consequently, affects their overall academic performance. Students have also addressed the load assignments as another challenge. This study discussed online identity in language classes during the pandemic which has not been explored in the recent COVID-19- related literature. The findings showed interesting data on online identity and anonymity. Participants preferred to keep their camera off to protect their privacy. Peer pressure was also another cause in an environment where switching off the cameras is the norm! The findings also showed that switching off the camera helped participants improve their participation levels and reduced the stress levels during the online class. Further research to explore this area, which is not within the scope of this research, is of great significance to deal with the dilemma of switching on/ switching off the cameras during online classes.

It is evident that the COVID-19 pandemic has paved the way for an educational reform. The world was forced to adopt online learning after the outbreak of the pandemic and the global closure of educational institutions. Yet, this sudden and forced shift, as Zhao (2020) described, has been the "catalyst" to revisit our educational systems and reconsider the value of distance learning by viewing it as a necessity rather than a luxury.

The recommendations below are made in relation to the major aspects that have been highlighted in this study as they are the key factors that should be considered when working on enhancing the effectiveness of the online classes' experience.

1. Connectivity: It is apparent that connectivity has been the most recurrent challenge that students face in distance learning. Losing the ability to connect online means losing the opportunity to be part of this learning mode. Students from remote villages in Oman have repeatedly expressed frustrations and concerns about the weak internet signal. This has pushed them to either move to a better place where the connection is more stable or constantly buy internet data packages that cost them a considerable amount of money. Thus, working on strengthening the internet network in Oman is key to provide equitable access to learning. It is also significant to support students with low income and provide them with the necessary digital infrastructure.

2. Communication with teachers and classmates: As stated in literature, establishing sufficient communication and collaboration between teachers and their students is critical to the success of the online learning experience. As Martin (2020) suggested, three channels of communication can be utilized to enhance interpersonal communication. The interpersonal channel can be used here to support students emotionally and get to know more about them. For example, instant live poll tools can be used to promote interaction in online classes such as Mentimeter, Padlet, Kahoot, Poll Everywhere and Pigeonhole Live. Teachers can use these tools to promote interaction between students and get updates on students' academic progress, concerns and interests. WhatsApp has been proved to be a promising and favorable communication tool to use with students. Yet, as shown in the findings, it is essential, for WhatsApp and other social platforms to serve the purpose, that teachers establish a good rapport with students and help students build a good rapport with peers. Thus, students feel emotionally committed to offer help and support each other when needed. Providing social forums, collaborative learning and project-based learning can also help humanising distance learning as suggested by Dhawan (2020). 
3. Learning environment and learning experience: Students need to feel secure and their privacy is protected in order to thrive in their distance education. Providing the appropriate and sufficient digital infrastructure is fundamental to achieving this. In addition, content and instruction channels, proposed by Marin (2020), can also be applied. Teachers need to provide interesting and suitable content and an appropriate load of instructional content, so students don't feel overwhelmed. Deadlines should not be tight, so students have enough time to work on their assignments. Most importantly, students should be taught how to be autonomous life thinkers, so they tackle sudden changes with less intensity. They also need to learn how to manage their time, be self-regulated and stay focused. Similarly, teachers need to be open to changes and ready to adjust their teaching pedagogies and styles when necessary.

With regard to language skills, findings showed that writing is the most challenging skill to learn online. Therefore, it is recommended that CPS administration represented in the program coordinators investigate this further and identify the reasons making this skill hard to learn online. It could be the load of instructions given to students, or trying to achieve all the learning outcomes targeted during face-to-face instruction without adjusting them in light of the shift to online learning. There could be a need to redesign the whole approach to teaching writing online at CPS to make it less challenging for students and teachers. What can be confirmed from the findings of this paper is that receiving feedback is not an issue for students at CPS which is a practice that is worth encouraging and sharing with teachers involved in a similar context.

4. Online identity: Findings revealed that some language learners preferred to switch off their camera because they did not want to get their home privacy exposed to their classmates. They also thought that switching off the camera helped them feel less stressed. Thus, it is paramount to explore this area further by focusing on the potentials and challenges of switching on the camera during the synchronous classes.

5. Assessment: It is believed that assessment is the prime source of stress and anxiety in the academic life. In online settings, students feel stressed because of various reasons. Having many assignments with tight deadlines increases stress and reduces the quality of work. Considering the nature of online learning, teachers need to give short assignments with more flexible deadlines.

6. Stress and anxiety: Students' mental health should be given proper attention, especially during crises, when distance learning becomes the online available learning mode to adopt which comes with additional challenges. Anxiety, stress, loneliness and disconnectedness are the most prominent challenges. Therefore, the role of student affairs officers and e-communities should be effectively activated. Students should know whom to contact if they feel they struggle emotionally.

In conclusion, to answer the main question: 'Are students thriving or surviving?', it is fortunate that the findings have shown that our students at CPS have the potentials to thrive during the online learning experience. This is on the condition of minimizing the challenges caused by connectivity, disconnectedness and assignments load which increase the anxiety level and eventually may prevent students from thriving. Establishing a relaxing learning environment is key to students' success and it allows them to get the most out of the online learning experience, especially during the time of crisis.

\section{References}

[1] Agung, A S N., Surtikanti, M W., Quinones, C. (2020). Students' Perception of Online Learning during COVID-19 Pandemic: A Case Study on the English Students of STKIP Pamane Talino. Jurnal Sosial dan Humaniora [Journal of Social Sciences and Humanities], 10(2), $225-235$.

http://dx.doi.org/10.31940/soshum.v10i2.1316

[2] Al Damen, M. T. (2020). The Effectiveness of Teacher Electronic Feedback in Asynchronous Teaching: A Case Study of Foundation Students at Sultan Qaboos University. Arab World English Journal, 2, 64-83. https://doi.org/10.24093/awej/mec2.5

[3] Al Damen, T. M.. (2020). The Effectiveness of Teacher Electronic Feedback in Asynchronous Teaching: A Case Study of Foundation Students at Sultan Qaboos UniversityArab World English Journal (AWEJ) Proceedings of 2ndMEC TESOL Conference 2020. 64-83. DOI:

https://dx.doi.org/10.24093/awej/MEC2.5

[4] Al Hosni, J. (2013). ESL Online Courses: A New Space for Redefining Social Identities. INTESOL Journal (ITJ), 10(1).

https://journals.iupui.edu/index.php/intesol/issue/view/690

[5] Asmara, R. (2020). Teaching English in a virtual classroom using WhatsApp during covid-19 pandemic. Language and Education Journal, 5(1), 16-27. http://ejournal.uniski.ac.id/index.php/LEJ/article/view/152

[6] Barker, L. (2020). Learn why today's new remote teaching experience is not the same as established online courses. Grantham University. https://www.grantham.edu/blog/remote-teaching-vs-online-learning-in-higher-educationtoday/.

[7] Berrocoso, J., Arroyo, M., Videla, C. \& Cevallos,M. (2020). Trends in Educational Research about e-Learning: A Systematic Literature Review (2009-2018). Sustainability 2020, 12(12), 1-23. https://doi.org/10.3390/su12125153

[8] Byun, S. \& Slavin, R. E. (2020). Educational Responses to the COVID-19 Outbreak in South Korea. Best Evid Chin Edu, 5(2), 665-680. 
[9] Dhawan, S. (2020). Online Learning: A Panacea in the Time of COVID-19 Crisis. Journal of Educational Technology Systems, 49(1), 5-22. https://doi.org/10.1177/0047239520934018

[10] Díaz. M, \& Lee. C, (2020). What Technology Can and Can't Do for Education: A Comparison of 5 Stories of Success. Inter-American Development Bank.

[11] Erarslan, A., \& Topkaya, E. Z. (2017). EFL students' attitudes towards e-learning and effect of an online course on students' success in English. The Literacy Trek, 3(2), 80-101.

[12] Fedynich, L., Bradley, k. \& Bradley, J. (2015). Graduate Students' Perceptions of Online Learning. Research in Higher Education Journal, 27, 113. https://files.eric.ed.gov/fulltext/EJ1056187.pdf

[13] Fong, C. J. (2008). Identity issues in ESL online chat rooms: A cautionary case. https://webspace.utexas.edu

[14] Fung, F. M., Magdeline, N. T. T., \& Kamei, R. K. (2020). How to create_engaging online learning amid COVID-19 pandemic: lessons from Singapore. The_Conversation. https://theconversation.com/how-to-create-engaging-online-learning-amid-covid-19-pandemic-lessons-fromsingapore-138979

[15] Gunn, C., McSporran, M., Macleod, H., \& French, S. (2003). Dominant or different: Gender issues in computer supported learning. Journal of Asynchronous Learning Networks, 7(1), 14-30.

[16] Hapsari, C. T. (2021). Distance learning in the time of Covid-19: Exploring students' anxiety. ELT Forum: Journal of English Language Teaching, 10(1), 40-49. https://doi.org/10.15294/elt.v10i1.45756

[17] Hodges, C., Moore, S., Lockee, B., Trust, T., \& Bond, A. (2020). The Difference between Emergency Remote Teaching and Online Learning. Educause Review. Retrieved 15 th April 2021 from https://er.educause.edu/articles/2020/3/the-difference-between-emergency-remote-teachingand-onlinelearning

[18] Kaid, J., \& Bin-Hady, W. (2019b). A Study of EFL Students' Attitudes, Motivation and Anxiety towards WhatsApp as a Language Learning Tool. Arab World English Journal, 5, 289-298. https://doi.org/10.24093/awej/call5.19

[19] Kaisara, G. \& Bwalya, K. J. (2021). Investigating the E-learning challenges faced by students during Covid-19 in Namibia. International Journal of Higher Education, 10(1), 308-318. https://doi.org/10.5430/ijhe.v10n1p308

[20] Khlaif, Z., \& Salha, S. (2020). The unanticipated challenges of developing countries in Covid-19 crisis: A brief report. Interdisciplinary Journal of Virtual Learning in Medical Sciences, 11(2), 130-134.

[21] Lam, W. S. E. (2004). Second language socialization in a bilingual chat room: Global and local considerations. Language Learning \& Technology, 8(3), 44-65.

[22] Leng, P., Khieng, S., \& Water, T. (2020). Going digital - The second phase of HE transformation. University World News.

https://www.universityworldnews.com/post.php?story=20200623154410596

[23] Li, C. \& Lalani, F. (2020). The COVID-19 pandemic has changed education forever. This is how. World Economic Forum.

https://www.weforum.org/agenda/2020/04/coronavirus-education-global-covid19-online-digital-learning/

[24] Mahyoob, M. (2020). Challenges of e-Learning during the COVID-19 Pandemic Experienced by EFL Learners. Arab World English Journal, 11(4), 351-362. https://doi.org/10.24093/awej/vol11no4.23

[25] Martin, A. (2020). How to optimise online learning in the age of Coronavirus. UNSW Newsroom. https://newsroom.unsw.edu.au/news/socialaffairs/how-optimise-online-learning-age-coronavirus.

[26] Melvina, M., Lengkanawati, N, Wirza, Y, Alicia, D \& Yulmiati, Y. (2020). EFL Learners' View on Online Learning Implementation During Covid19 Outbreaks. Advances in Social Science, Education and Humanities Research, 513, 351-357. https://doi.org/10.2991/assehr.k.201230.130

[27] Michinov, N., Michinov, E., \& Toczek-Capelle, M. C. (2004). Social identity, group processes, and performance in synchronous computermediated communication. Group Dynamics, 8, 27-39.

[28] Noor, S., Isa, F.M., \& Mazhar F.F. (2020). Online teaching practices during the Covid-19 pandemic. Educational Process International Journal, 9(3), 169-184, DOI: 10.22521/edupij.2020.93.4

[29] Osman, M. E. (2020). Global impact of COVID-19 on education systems: the emergency remote teaching at Sultan Qaboos University. Journal of Education for Teaching, 46(4), 463-471. https://doi.org/10.1080/02607476.2020.1802583

[30] Pellegrini, M., Uskov, V., \& Casalino, N. (2020). Reimagining and Re-Designing the Post COVID-19 Higher Education Organizations to Address New Challenges and Responses for Safe and Effective Teaching Activities. Law and Economics Yearly Review Journal, $219-248$.

https://papers.ssrn.com/sol3/papers.cfm?abstract id=3659062

[31] Prensky, M. (2001). Digital natives, digital immigrants. From On the Horizon. MCB University Press, 9(5), 1-6.

[32] Shisley, S. (2020, May). Emergency Remote Learning Compared to Online Learning. Learning Solutions Magazine.

https://learningsolutionsmag.com/articles/emergency-remotelearning-compared-to-online-learning.

[33] SQU Annual Report. (2019). Sultan Qaboos University. https://www.squ.edu.om/Portals/0/pdf/Annual\%20Report\%202019.pdf

[34] Sullivan, P. (2002). "It's easier to be yourself when you are invisible": Female college students discuss their online classroom experiences. Innovative Higher Education, 27(2), 129-144.

[35] Sun, S Y H. (2014). Learner perspectives on fully online language learning. Distance Education, 35(1), 18-42.

https://doi.org/10.1080/01587919.2014.891428

[36] The Evolution of Distance Education in 2020. (2020). The University of Kensas. https://educationonline.ku.edu/community/distanceeducation-evolution-in-2020

[37] Tuncay, N. \& Uzunboylu, H. (2010). Anxiety and Resistance in Distance Learning. Cypriot Journal of Educational Sciences, 5(2), 142-150 [38] Ullah, O., Khan, W \& Khan, A. (2017). Students' Attitudes towards Online Learning at Tertiary Level. PUTA-Humanities and Social Sciences, 25(1-2)

[39] UNESCO (2020). UNESCO Report reveals lack of education laws to ensure inclusive education during COVID-19.

https://en.unesco.org/news/unesco-report-reveals-lack-educationlaws-ensure-inclusive-education-during-covid-19.

[40] Zhao, Y. (2003). Recent developments in technology and language learning: A literature review and meta-analysis. CALICO Journal, 21(1), 727.

[41] Zhao, Y. (2020). COVID as a catalyst for educational reform. Prospects 49 (2020), 29-33 https://doi.org/10.1007/s 11125-020-09477-y 